\title{
Genetic polymorphisms of paraoxonase1 192 and glutathione peroxidase 197 enzymes in familial Mediterranean fever
}

\author{
F. Öktem ${ }^{1}$, H. Anıl ${ }^{2}$, R. Sütciü ${ }^{3}$ and A.E. Kuybulu ${ }^{2}$ \\ ${ }^{1}$ Department of Pediatric Nephrology, School of Medicine, \\ Bezmialem Vakif University, Istanbul, Turkey \\ ${ }^{2}$ Department of Pediatric Nephrology, School of Medicine, \\ Suleyman Demirel University, Isparta, Turkey \\ ${ }^{3}$ Department of Biochemistry and Clinical Biochemistry, \\ School of Medicine, İzmir Katip Celebi University, Izmir, Turkey \\ Corresponding author: F. Öktem \\ E-mail: oktemfaruk@hotmail.com
}

Genet. Mol. Res. 13 (2): 3292-3300 (2014)

Received February 5, 2013

Accepted September 13, 2013

Published April 29, 2014

DOI http://dx.doi.org/10.4238/2014.April.29.7

\begin{abstract}
Familial Mediterranean fever (FMF) is an autosomal recessive disorder and is the most frequent of the periodic febrile inflammatory syndromes. The pathogenesis of the disease is not completely understood, even though the FMF gene has been identified. Oxidative stress and inflammation may play a role in the pathogenesis of FMF. We investigated gene polymorphisms of the antioxidative enzymes, glutathione peroxidase (GPX) and paraoxonase (PON) in FMF patients, and possible associations with FMF pathogenesis. Sixty FMF patients during an attack-free period and 51 healthy children as the control group were included in our study. PON1 Q/R192 and GPX1 Pro197Leu gene polymorphisms were assayed. Blood urea nitrogen, creatinine and serum lipid profile were also measured. PON1 Q/R192 genotype distribution was $52 \% \mathrm{QQ}, 46 \% \mathrm{QR}$ and $2 \% \mathrm{RR}$ in the FMF group and $45 \% \mathrm{QQ}, 45 \% \mathrm{QR}$ and $10 \% \mathrm{RR}$ in the control group $(\mathrm{P}>$
\end{abstract}


0.05). GPX1 Pro197Leu genotype distribution was 28\% PP, 57\% PL, $15 \%$ LL in the FMF group and $18 \%$ PP, 53\% PL, 29\% LL in the control group $(\mathrm{P}>0.05)$. Blood urea nitrogen, serum creatinine, lipid levels, and the distribution of PON1 Q/R192 and GPX1 Pro197Leu genotypes were similar in the two groups. We conclude that the PON1 Q/R192 and GPX1 Pro197Leu gene polymorphisms are not important risk factors in the development of FMF. However, larger studies are warranted to validate these conclusions.

Key words: Familial Mediterranean fever; Inflammation; Paraoxonase; Oxidative stress; Glutathione peroxidase; Gene polymorphism

\section{INTRODUCTION}

Familial Mediterranean fever (FMF) is an autosomal recessive hereditary disease that is characterized by recurrent attacks of fever and peritonitis, pleuritis, arthritis, or erysipelas-like skin lesions (Livneh et al., 1997). The gene responsible for FMF is designated as Mediterranean fever gene (MEFV) and mapped to a small interval on the short arm of chromosome 16 (Centola et al., 2000). However, the exact pathogenesis of the acute episodes of FMF is still unknown. Many studies have been established to clarify the mechanism of the inflammatory attacks in FMF, but possible factors triggering these attacks have not yet been identified (Centola et al., 2000). Some of the latest studies have suggested that sustained inflammation and oxidative stress are present during attack-free periods, and this is important in the further understanding of the disease pathogenesis (Bagci et al., 2004). Increased oxidative stress has an important role in the development of various inflammatory reactions such as ischemia-reperfusion injury, metabolic diseases and pathological conditions (Ozguner et al., 2005; Hashemi et al., 2010; Oktem et al., 2011). Increased oxidative stress has been demonstrated in patients with FMF (Karaguezyan et al., 1996; Kirkali et al., 2008). An imbalance in oxidant and antioxidant mechanisms may influence cellular sensitivity to free radical damage and alter susceptibility to disease.

Human paraoxonase (PON1) is an antioxidant enzyme located on high density lipoprotein (Adkins et al., 1993; Hashemi et al., 2010). It has been associated with the detoxification of organophosphates and possibly in the prevention of low-density lipoprotein oxidation (Biasioli et al., 2003). Two major genetic polymorphisms of PON1 have been described due to glutamine or arginine at position $192(\mathrm{Q} / \mathrm{R} 192)$ and methionine or leucine at position $55(\mathrm{~L} / \mathrm{M})$ (Uyar et al., 2011). These polymorphisms are associated with difference in serum activities and concentrations of the enzymes (Adkins et al., 1993). PON1 activity and polymorphisms have been found to be associated with several diseases including nephrological and rheumatological diseases such as chronic renal failure, focal segmental glomerulosclerosis, systemic lupus erythematosus, Behcet disease, rheumatoid arthritis, and Henoch-Schönlein purpura, as well as other diseases such as coronary artery disease, cerebral infarct, dementia, Alzheimer's disease, type 2 diabetes mellitus, hyperthyroidism, and liver cirrhosis (Adkins et al., 1993; Kobayashi et al., 2002; Biasioli et al., 2003; Hashemi et al., 2010).

Human glutathione peroxidase (GPX) is an antioxidant enzyme that is expressed in blood vessels (Suzen et al., 2010). Its role is protection of cells against oxidative damage by reducing hydrogen peroxide and a wide range of organic peroxidases to $\mathrm{H}_{2} \mathrm{O}_{2}$ with reduced glutathione. The 
cytosolic form of GPX1 is a selenium-dependent enzyme. This enzyme is encoded by the GPX1 gene, which is located on chromosome $3 \mathrm{p} 21$, and one of the major genetic polymorphisms of this gene has been described as a leucine or proline at position 197 (Jefferies et al., 2005). This polymorphism continues to be questioned in relation to many diseases. In the autoinflammatory disease groups and FMF, there are no data on the GPX1 Pro197Leu gene polymorphism.

The aim of the present study was to compare the frequency of the PON1 Q/R192 and GPX1 Pro197Leu gene polymorphisms in Turkish children with FMF and healthy controls. To our knowledge, this is the first study to investigate these polymorphisms in FMF patients.

\section{MATERIAL AND METHODS}

The study was carried out at Suleyman Demirel University Medical Faculty between July 2008 and July 2010 prospectively. Children with a diagnosis of FMF $(\mathrm{N}=60)$ being followed up in the pediatric nephrology clinic and healthy volunteers without the history of any chronic disease and whom we called control group $(\mathrm{N}=51)$ were included in this study. The project was carried out with the approval of the medical human Ethics Committee of the Suleyman Demirel University Faculty of Medicine, and all participants and/or their parents gave informed consent. The patients or their parents received a standard questionnaire containing questions regarding the age at FMF diagnosis, family history, origin, treatment, and the duration between the onset of symptoms and diagnosis. All patients were from the Mediterranean area of Turkey. None of the study participants was obese, a passive smoker, or under any medications known to interfere with lipid metabolism.

\section{Patients}

The patient group consisted of 60 children ( 33 boys, 27 girls) with a mean age of 11.5 \pm 4.4 years at the time of diagnosis. All patients with FMF met Tel Hashomer criteria of the disease (Livneh et al., 1997). All patients were included in the study during an attack-free period. For the present study, patients were classified into three groups according to mutations; M694V homozygotes (16 patients, 27\%), compound heterozygotes (24 patients, $40 \%$ ) and heterozygote mutations + a patient with no mutation (20 patients, $33 \%)$. The control group consisted of 28 boys and 23 girls with mean age of $7.7 \pm 4.3$ years, without any family history of FMF or other chronic diseases among first-degree relatives. Also, all patients were further classified according to their PON1 Q/R192 gene polymorphism, namely QQ, QR and RR genotypes, and GPX1 Pro197Leu gene polymorphism namely PP, PL and LL genotypes. Venous blood samples were drawn to determine complete blood count, erythrocyte sedimentation rate, blood urea nitrogen $(\mathrm{BUN})$, creatinine $(\mathrm{Cr})$, uric acid, C-reactive protein $(\mathrm{CRP})$, and triglyceride, total cholesterol, low-density lipoprotein and high-density lipoprotein cholesterol. Measurements were made using standard spectrophotometric methods (autoanalyzer, Abbott Aeroset, USA) in the hospital clinical laboratory.

\section{Genotyping method for the PON1 Q/R192 polymorphism}

Genomic DNA was extracted from peripheral blood samples containing EDTA by the salting out method (Miller et al., 1988). Genotypes for PON1 192 were determined by poly- 
merase chain reaction (PCR) and restriction enzyme digestion (Mackness et al., 1996). For the 192 polymorphism, sense primer 5'-TAT TGT TGC TGT GGG ACC TGAG-3' and antisense primer 5'-GAC ATA CTT GCC ATC GGG TGA A-3', which encompass the 192 polymorphic region of the human PON1 gene, were used. The PCR mixture contained 100 ng DNA template, $0.5 \mu \mathrm{M}$ of each primer, $1.5 \mathrm{mM} \mathrm{MgCl}, 200 \mu \mathrm{M}$ dNTPs, and $1 \mathrm{U}$ Taq DNA polymerase (MBI Fermentas). After denaturizing the DNA for $5 \mathrm{~min}$ at $94^{\circ} \mathrm{C}$, the reaction mixture was subjected to 35 cycles of denaturation for $1 \mathrm{~min}$ at $95^{\circ} \mathrm{C}, 1 \mathrm{~min}$ annealing at $60^{\circ} \mathrm{C}$ and $1 \mathrm{~min}$ extension at $72^{\circ} \mathrm{C}$ for the 192 genotype. The 199-bp PCR product was digested with $8 \mathrm{U} \mathrm{BspI}$ restriction endonuclease (New England Biolabs) overnight at $55^{\circ} \mathrm{C}$ and the digested products separated by electrophoresis on a $4 \%$ agarose gel and visualized using ethidium bromide. The $\mathrm{R}$ genotype contains a unique $B s p \mathrm{I}$ restriction site, which results in 135- and 64-bp products and the Q genotype cannot be cut, allowing the PON1 Q/R192 genotype to be determined.

\section{Genotyping method for the GPX1 Pro197Leu polymorphism}

Genotypes for GPX1 Pro197Leu were determined by PCR and restriction enzyme digestion. For the Pro197Leu polymorphism, sense primer 5'-TTA TGA CCG ACC CCA AGC TCA-3' and antisense primer 5'-ACA GCA GCA CTG CAA CTG CC-3'. The PCR mixture contained $100 \mathrm{ng}$ DNA template, 20 pmol primer, $1.5 \mathrm{mM} \mathrm{MgCl}_{2}, 200 \mu \mathrm{M}$ dNTPs, and $1 \mathrm{U}$ Taq DNA polymerase (MBI Fermentas). After denaturizing the DNA for 3 min at $94^{\circ} \mathrm{C}$, the reaction mixture was subjected to 35 cycles of denaturation for $30 \mathrm{~s}$ at $94^{\circ} \mathrm{C}, 1 \mathrm{~min}$ annealing at $58^{\circ} \mathrm{C}$ and $1 \mathrm{~min}$ extension at $72^{\circ} \mathrm{C}$ for the Pro197Leu genotype.

\section{Statistical analysis}

Statistical analyses were performed using the SPSS version 15.0 for Windows (SPSS Inc., Chicago, IL, USA). All data are reported as means \pm standard deviation. The non-parametric Mann-Whitney U-test was used to compare variables, including duration, age, WBC (white blood cell count), CRP, erythrocyte sedimentation rate, BUN, Cr, and cholesterol levels. Genotype comparisons of different groups were made using the chi-square test and the Fisher exact test (for cases with insufficient expected cell frequencies). Because of the small number of patients in each genotype group, the data were pooled according to case control-study-dominant model. In addition, estimated relative risk odds ratio (OR) and confidence interval (CI) were measured. QQ genotype frequency was compared with $\mathrm{QR}+\mathrm{RR}$ genotype frequency and $\mathrm{PP}$ genotype frequency was compared with PL+LL genotype frequency. $\mathrm{P}<0.05$ was accepted as significant.

\section{RESULTS}

The demographic characteristics of the FMF patients and healthy controls are shown in Table 1. WBC, hemoglobin, hemotocrit, serum CRP, BUN, Cr, and lipid levels of each case were in the normal range according to their ages. There were no significant differences between groups for gender, age, hemoglobin, hemotocrit, BUN, Cr, and serum lipid levels (Table 1). Nineteen of FMF patients and one of control subjects had elevated erythrocyte sedimentation rates $(\geq 15$ $\mathrm{mm} / \mathrm{h})(31$ vs $1.9 \%, \mathrm{P}=0.0001)$. There were no significant differences in acute phase reactants considering CRP levels and WBC between the FMF and control groups. All of those included in 
the patient group were free of attack for at least 6 months. The PON1 Q/R192 genotype frequencies for FMF and control groups are shown in Table 2. Children with FMF and the control group had similar PON1 Q/R192 genotype distribution (QQ: 52 vs 45\%; QR: 46 vs 45\%; RR: 2 vs 10\%, respectively) (Table 2). The frequency of the QQ genotype in the FMF group was comparable with the control group (Table 2) (52vs 45\%, $\mathrm{P}>0.05$ ). No significant difference existed in $\mathrm{Q} / \mathrm{R}$ allele distribution between the two groups $(0.75 / 0.25$ vs $0.68 / 0.32$, respectively; $\mathrm{P}>0.05)$. GPX1 Pro197Leu genotype frequencies and distribution in children with FMF and the control group are shown in Table 3. The most frequent GPX1 Pro197Leu genotype was PL (57\%), followed by PP $(28 \%)$ and LL $(15 \%)$ in children with FMF. The gene frequency for GPX1 Pro197Leu polymorphisms in controls and FMF patients was not different. Also, there was no significant difference between FMF and control groups in $\mathrm{P} / \mathrm{L}$ allele distribution $(0.57 / 0.43$ vs $0.44 / 0.56$, respectively; $\mathrm{P}>0.05)$. When subgroups carried the M694V homozygous mutation $(\mathrm{N}=16)$ and if healthy control group were separately compared regarding the results of PON1 192 and GPX1 Pro197Leu genotype, no significant differences were found between the groups (respectively $\mathrm{P}>0.05$, OR: 0.9, 95\% CI: 0.3-2.9 and P > 0.05, OR: 2.8, 95\% CI: 0.8-9.7).

Table 1. Clinical and biochemical characteristics of children with FMF and the control group.

\begin{tabular}{|c|c|c|c|}
\hline & FMF group $(\mathrm{N}=60)$ & Control group $(\mathrm{N}=51)$ & $P$ \\
\hline Boy/girl & $33 / 27$ & $28 / 23$ & NS** \\
\hline Age (years) & $11.5 \pm 4.4$ & $7.7 \pm 4.3$ & NS* \\
\hline Age at onset (years) & $5.4 \pm 3.9$ & - & \\
\hline Age at diagnosis (years) & $10.9 \pm 9.0$ & - & \\
\hline Duration between onset and diagnosis (years) & $5.5 \pm 8.1$ & - & \\
\hline Hematocrit & $39.01 \pm 0.53$ & $37.59 \pm 0.57$ & NS* \\
\hline Hemoglobin & $13.38 \pm 0.19$ & $13.49 \pm 0.19$ & NS* \\
\hline White blood cell count $\left(10^{3} / \mu \mathrm{L}\right)$ & $7.5 \pm 2.4$ & $7.5 \pm 2.9$ & NS* \\
\hline C-reactive protein $(\mathrm{mg} / \mathrm{L})$ & $4.4 \pm 5.4$ & $4.2 \pm 3.3$ & NS* \\
\hline Erythrocyte sedimentation rate $(\mathrm{mm} / \mathrm{h})$ & $10.2 \pm 11.2$ & $5.8 \pm 3.6$ & $0.001 *$ \\
\hline Blood urea nitrogen $(\mathrm{mg} / \mathrm{dL})$ & $11.0 \pm 2.8$ & $10.1 \pm 3.0$ & NS* \\
\hline Serum creatinine $(\mathrm{mg} / \mathrm{dL})$ & $0.6 \pm 0.1$ & $0.5 \pm 0.1$ & NS* \\
\hline Serum total cholesterol (mg/dL) & $148.9 \pm 27.4$ & $147.8 \pm 30.7$ & NS* \\
\hline Serum HDL cholesterol (mg/dL) & $42.2 \pm 10.3$ & $46.6 \pm 16.8$ & NS* \\
\hline Serum LDL cholesterol (mg/dL) & $84.3 \pm 21.3$ & $81.6 \pm 27.0$ & NS* \\
\hline Serum triglyceride $(\mathrm{mg} / \mathrm{dL})$ & $106.7 \pm 56.4$ & $91.0 \pm 41.7$ & NS* \\
\hline
\end{tabular}

Variables are reported as means \pm standard deviation. FMF $=$ familial Mediterranean fever. *Mann-Whitney U-test; **Chi-square test; NS = not significant.

Table 2. Distribution of the PON1 Q/R192 gene polymorphism and allele frequencies in patients with FMF and the control group.

\begin{tabular}{|c|c|c|c|c|c|}
\hline & \multicolumn{3}{|c|}{ PON1 192 genotypes [N (\%)] } & \multicolumn{2}{|c|}{ Alleles [N (\%)] } \\
\hline & QQ & QR & $\mathrm{RR}$ & Q & $\mathrm{R}$ \\
\hline FMF $(\mathrm{N}=60)$ & $31(52)$ & $28(46)$ & $1(2)$ & $90(75)$ & $30(25)$ \\
\hline M694V homozygote $(\mathrm{N}=16)$ & $7(44)$ & $8(50)$ & $1(6)$ & $22(69)$ & $10(31)$ \\
\hline Compound heterozygote $(\mathrm{N}=24)$ & $14(58)$ & $10(42)$ & $0(0)$ & $38(79)$ & $10(21)$ \\
\hline Heterozygote and no mutation $(\mathrm{N}=20)$ & $10(50)$ & $10(50)$ & $0(0)$ & $30(75)$ & $10(25)$ \\
\hline \multirow[t]{2}{*}{ Control $(\mathrm{N}=51)$} & $23(45)$ & $23(45)$ & $5(10)$ & $69(68)$ & $33(32)$ \\
\hline & QQ & $\mathrm{QR}+\mathrm{RR}$ & & Q & $\mathrm{R}$ \\
\hline OR & 1.301 & 0.768 & & 1.435 & 0.697 \\
\hline $95 \% \mathrm{CI}$ & $0.616-2.751$ & $0.363-1.625$ & & $0.799-2.577$ & $0.388-1.252$ \\
\hline $\mathrm{P}$ & $\mathrm{NS}^{\mathrm{a}}$ & & & NS & \\
\hline
\end{tabular}

$\mathrm{PON}=$ paraoxonase $; \mathrm{FMF}=$ familial Mediterranean fever; $\mathrm{OR}=$ odds ratio $; \mathrm{CI}=$ confidence interval. ${ }^{\mathrm{a}} \mathrm{Chi}$ square or Fisher exact test (pooled data QQ vs QR+RR); NS = not significant. 


\begin{tabular}{|c|c|c|c|c|c|}
\hline & \multicolumn{3}{|c|}{ GPX1 Pro197Leu genotypes N (\%) } & \multicolumn{2}{|c|}{ Alleles N (\%) } \\
\hline & PP & PL & LL & $\mathrm{P}$ & $\mathrm{L}$ \\
\hline FMF $(\mathrm{N}=60)$ & $17(28)$ & $34(57)$ & $9(15)$ & $68(57)$ & $52(43)$ \\
\hline M694V homozygote $(\mathrm{N}=16)$ & $6(37)$ & $8(50)$ & $2(13)$ & $22(69)$ & $10(31)$ \\
\hline Compound heterozygote $(\mathrm{N}=24)$ & $7(29)$ & $15(63)$ & $2(8)$ & $38(79)$ & $10(21)$ \\
\hline Heterozygote and no mutation $(\mathrm{N}=20)$ & $4(20)$ & $11(55)$ & $5(25)$ & $30(75)$ & $10(25)$ \\
\hline \multirow[t]{2}{*}{ Control $(\mathrm{N}=51)$} & $9(18)$ & $27(53)$ & $15(29)$ & $45(44)$ & $57(56)$ \\
\hline & PP & $\mathrm{PL}+\mathrm{LL}$ & & $\mathrm{P}$ & $\mathrm{L}$ \\
\hline $\begin{array}{l}\text { OR } \\
95 \% \text { CI } \\
\text { P value }\end{array}$ & $\begin{array}{c}1.548 \\
0.740-4.597 \\
\mathrm{NS}^{\mathrm{a}}\end{array}$ & $\begin{array}{c}0.542 \\
0.218-1.351\end{array}$ & & $\begin{array}{c}1.656 \\
0.973-2.82 \\
\text { NS }\end{array}$ & $\begin{array}{c}0.604 \\
0.355-1.029\end{array}$ \\
\hline
\end{tabular}

$\mathrm{GPX}=$ glutathione peroxidase; FMF = familial Mediterranean fever; $\mathrm{OR}=$ odds ratio; $\mathrm{CI}=$ confidence interval. ${ }^{a}$ Chi square or Fisher exact test (pooled data PP versus PL+LL); NS = not significant.

\section{DISCUSSION}

It is already known that specific MEFV mutations are not the only determinants of the phenotype in FMF but also unknown environmental factors or possible modifying genes that could act as triggers in this disease. Potential modifying genes that may be involved in disease pathogenesis are oxidative stress genes. Associations between oxidative stress and FMF were previously studied and it was found that even in attack-free periods, patients were subject to a subclinical inflammation, an upregulation of neutrophils and oxidative burst (Bagci et al., 2004; Kirkali et al., 2008). Slightly elevated erythrocyte sedimentation rates in our patients also showed that continuous subclinical inflammation is present in FMF patients even when free of attack for at least 6 months and in the absence of mild anemia. Although measurement of CRP is well established to be the sensitive and active indicator of acute-phase response in FMF patients, we found similar CRP results in the two groups. CRP levels increase following an inflammatory condition within a short time and decrease rapidly. Therefore, in this study CRP results of patients may have been similar as in the control group.

During fever attacks, there is activation of acute phase reactions that result in neutrophilia and increase in serum amyloid A. Substantial influx of polymorphonuclear leukocytes into the affected tissues has also been observed (Tunca et al., 1999). Activated neutrophils generate reactive oxygen species including free radicals such as the highly reactive hydroxyl radical, which could cause oxidative damage (Ozguner et al., 2005; Kirkali et al., 2008). A few studies have shown that there is persistent inflammation in FMF patients, which causes oxidative damage (Tunca et al., 1999; Bagci et al., 2004). There is growing evidence indicating increased oxidative stress in FMF patients both in the remission period and in the attack period. In light of those data, this study aimed to investigate the association between FMF and genetic polymorphism at codon 192 in the PON1 gene encoding the PON1 enzyme, which is an indicator of inflammation, and the Pro197Leu polymorphism in the GPX1 gene encoding GPX1 enzyme, which is an indicator of oxidative damage.

In studies evaluating the effect of PON1 192 genotyping on lipid levels, it has been reported that the PON1 192 gene polymorphism is not a major inhibitor in the oxidation of low-density lipoprotein, and for this reason, it may not affect lipid levels (Kafadar et al., 2006; Kucukali et al., 2008). In the present study, there was no significant difference in serum lipid 
levels between the patients with FMF and the control group. Genotype distribution for the PON1 192 polymorphism of the control group in the present study was similar to the data obtained for the control groups of previously reported studies (Van Himbergen et al., 2004; Kafadar et al., 2006; Kucukali et al., 2008). However, we did not find any significant difference between the FMF group and the control group regarding PON1 192 polymorphism in terms of both QQ and QR+RR genotypes and the frequency of Q and R alleles. To our knowledge, this is the first study to investigate the association between the PON1 192 polymorphism and FMF. Therefore, we can speculate that PON1 192 genotypes were not associated with FMF, and that PON1 192 Q allele or QQ genotype is not a risk factor for patients with FMF. However, the results of the present study should certainly be confirmed by further studies, and other PON1 polymorphisms should be studied as well.

Inflammation, oxidative stress and free radicals are important in the pathogenesis of FMF. Although, the relationship between oxidative stress and FMF has been discussed in various studies, the association between antioxidant enzyme gene polymorphisms including GPX1 Pro197Leu and FMF has not been evaluated in any study to date. We hypothesized in the present study that a polymorphism in the sequence of an important antioxidant enzyme, GPX1, may influence the biological behavior of this enzyme and therefore the clinical diversity of FMF. However, the present study did not reveal any statistically significant correlation between the Pro197Leu polymorphism of the GPX1 gene and FMF. Our findings suggest that GPX1 Pro197Leu is not associated with the physiopathology and frequency of FMF. There are limited studies about the GPX1 Pro197Leu polymorphism in the literature (Hansen et al., 2005; Shinkai et al., 2004, 2006; Wei et al., 2011). These studies conducted on the GPX1 Pro197Leu polymorphism mostly include malignancies; however, results concerning the relationship between malignancies and the GPX1 Pro197Leu polymorphism are contradictory. In studies conducted on a group of diseases such as colorectal carcinoma, prostatic carcinoma, schizophrenia, and tardive dyskinesia, it has been stated that the GPX1 Pro197Leu polymorphism is not a major risk factor for these diseases (Hansen et al., 2005; Shinkai et al., 2004, 2006; Choi et al., 2007).

It was shown that the GPX1 Leu allele was less responsive than the Pro allele during stimulation of the GPX1 enzyme activity by selenium supplementation in vitro (Uyar et al., 2011; Wei et al., 2011). The presence of a more frequent Pro allelle may make FMF patients more vulnerable to oxidative stress. However, in the present study, there was no significant increase in frequencies of PP or P allele of the GPX1 Pro197Leu gene when compared with the control group.

Genetic variations in other defense genes may be important modifers in the relationship of GPX1 with FMF. Thus, other antioxidant enzymes such as manganese superoxide dismutase (MnSOD), catalase, and glutathione-S-transferase, as well as oxidant enzymes such as xanthine oxidase and myeloperoxidase as candidates for oxidant/antioxidant imbalance in FMF should be taken into account in future studies. Analyses in conjunction with other reactive oxygen species-related polymorphisms will help to fully elucidate the contribution of these genes to FMF. For a greater understanding of the pathogenesis of FMF, larger studies are needed to evaluate whether any variant of the GPX1 gene contributes to the disease. A basic understanding about the expression and regulation of antioxidant enzymes in FMF is necessary to develop therapeutic interventions to control oxidative stress. Also, further investigations are warranted in larger populations with other antioxidant enzymes including GPX3 and GPX4, MnSOD, and glutathione-S-transferases, as the underlying cause of FMF. 
There were some limitations of the present study to be considered. The activities or levels of PON and GPX enzymes were not measured, which may be considered important. However, PON and GPX enzyme activities are extremely unstable and affected by various environmental stimulations. Still, the determination of gene polymorphism frequencies confirmed the vulnerability of patients to oxidative stress in case of a stimulus. The present study was conducted with a relatively small number of patients. Larger studies evaluating PON1 192 and GPX1 Pro197Leu polymorphisms together with PON and GPX enzyme activity measurements in patients with FMF may be a guide to obtain more accurate results.

In conclusion, we did not find a relationship between FMF and PON1 192 and GPX1 Pro197Leu gene polymorphisms. Further studies with a large number of cases should be conducted to evaluate the role of these gene polymorphisms as well as other oxidative stress gene polymorphisms for understanding the pathogenesis of FMF. Furthermore, there is a need to include other ethnicities and nationalities to confirm our findings, and to fully examine the possible relationship between antioxidant enzyme gene polymorphisms and FMF.

\section{REFERENCES}

Adkins S, Gan KN, Mody M and La Du BN (1993). Molecular basis for the polymorphic forms of human serum paraoxonase/arylesterase: glutamine or arginine at position 191, for the respective A or B allozymes. Am. J. Hum. Genet. 52: 598-608.

Bagci S, Toy B, Tuzun A, Ates Y, et al. (2004). Continuity of cytokine activation in patients with familial Mediterranean fever. Clin. Rheumatol. 23: 333-337.

Biasioli S, Schiavon R, Petrosino L, De Fanti E, et al. (2003). Paraoxonase activity and paraoxonase 1 gene polymorphism in patients with uremia. ASAIO J. 49: 295-299.

Centola M, Wood G, Frucht DM, Galon J, et al. (2000). The gene for familial Mediterranean fever, MEFV, is expressed in early leukocyte development and is regulated in response to inflammatory mediators. Blood 95: 3223-3231.

Choi JY, Neuhouser ML, Barnett M, Hudson M, et al. (2007). Polymorphisms in oxidative stress-related genes are not associated with prostate cancer risk in heavy smokers. Cancer Epidemiol. Biomarkers Prev. 16: 1115-1120.

Hansen R, Saebø M, Skjelbred CF, Nexø BA, et al. (2005). GPX Pro198Leu and OGG1 Ser326Cys polymorphisms and risk of development of colorectal adenomas and colorectal cancer. Cancer Lett. 229: 85-91.

Hashemi M, Moazeni-Roodi AK, Fazaeli A, Sandoughi M, et al. (2010). The L55M polymorphism of paraoxonase-1 is a risk factor for rheumatoid arthritis. Genet. Mol. Res. 9: 1735-1741.

Jefferies S, Kote-Jarai Z, Goldgar D, Houlston R, et al. (2005). Association between polymorphisms of the GPX1 gene and second primary tumours after index squamous cell cancer of the head and neck. Oral. Oncol. 41: 455-461.

Kafadar AM, Ergen A, Zeybek U, Agachan B, et al. (2006). Paraoxonase 192 gene polymorphism and serum paraoxonase activity in high grade gliomas and meningiomas. Cell Biochem. Funct. 24: 455-460.

Karaguezyan KG, Haroutjunian VM, Mamiconyan RS, Hakobian GS, et al. (1996). Evidence of oxidative stress in erythrocyte phospholipid composition in the pathogenesis of familial Mediterranean fever (periodical disease). $J$. Clin. Pathol. 49: 453-455.

Kirkali G, Tunca M, Genc S, Jaruga P, et al. (2008). Oxidative DNA damage in polymorphonuclear leukocytes of patients with familial Mediterranean fever. Free Radic. Biol. Med. 44: 386-393.

Kobayashi S, Inoue N, Azumi H, Seno T, et al. (2002). Expressional changes of the vascular antioxidant system in atherosclerotic coronary arteries. J. Atheroscler. Thromb. 9: 184-190.

Kucukali CI, Aydin M, Ozkok E, Orhan N, et al. (2008). Paraoxonase-1 55/192 genotypes in schizophrenic patients and their relatives in Turkish population. Psychiatr. Genet. 18: 289-294.

Livneh A, Langevitz P, Zemer D, Zaks N, et al. (1997). Criteria for the diagnosis of familial Mediterranean fever. Arthritis Rheum. 40: 1879-1885.

Mackness MI, Mackness B, Durrington PN, Connelly PW, et al. (1996). Paraoxonase: biochemistry, genetics and relationship to plasma lipoproteins. Curr. Opin. Lipidol. 7: 69-76.

Miller SA, Dykes DD and Polesky HF (1988). A simple salting out procedure for extracting DNA from human nucleated cells. Nucleic Acids Res. 16: 1215.

Oktem F, Kirbas A, Armagan A, Kuybulu AE, et al. (2011). Lisinopril attenuates renal oxidative injury in L-NAME- 
induced hypertensive rats. Mol. Cell. Biochem. 352: 247-253.

Ozguner F, Oktem F, Ayata A, Koyu A, et al. (2005). A novel antioxidant agent caffeic acid phenethyl ester prevents long-term mobile phone exposure-induced renal impairment in rat. Prognostic value of malondialdehyde, N-acetylbeta-D-glucosaminidase and nitric oxide determination. Mol. Cell. Biochem. 277: 73-80.

Shinkai T, De Luca V, Zai G, Shaikh S, et al. (2004). No association between the Pro197Leu polymorphism in the glutathione peroxidase (GPX1) gene and schizophrenia. Psychiatr. Genet. 14: 177-180.

Shinkai T, Muller DJ, De Luca V, Shaikh S, et al. (2006). Genetic association analysis of the glutathione peroxidase (GPX1) gene polymorphism (Pro197Leu) with tardive dyskinesia. Psychiatry Res. 141: 123-128.

Suzen HS, Gucyener E, Sakalli O, Uckun Z, et al. (2010). CAT C-262T and GPX1 Pro198Leu polymorphisms in a Turkish population. Mol. Biol. Rep. 37: 87-92.

Tunca M, Kirkali G, Soyturk M, Akar S, et al. (1999). Acute phase response and evolution of familial Mediterranean fever. Lancet 353: 1415.

Uyar OA, Kara M, Erol D, Ardicoglu A, et al. (2011). Investigating paraoxonase-1 gene Q192R and L55M polymorphism in patients with renal cell cancer. Genet. Mol. Res. 10: 133-139.

Van Himbergen T, Roest M, De Waart F, de Graaf J, et al. (2004). Paraoxonase genotype, LDL-oxidation and carotid atherosclerosis in male life-long smokers. Free Radic. Res. 38: 553-560.

Wei HL, Pei JR, Jiang CX, Zhou LW, et al. (2011). Analysis of glutathione peroxidase 1 gene polymorphism and Keshan disease in Heilongjiang Province, China. Genet. Mol. Res. 10: 2996-3001. 